\title{
Knowledge and Behaviour of Tooth Loss and Artificial Teeth among Females Residing in Jeddah, Saudi Arabia
}

\author{
SALMA A. BAHANNAN, BDS, MS \\ Department of Oral \& Maxillofacial Rehabilitation, Faculty of Dentistry, \\ King Abdulaziz University, Jeddah, Saudi Arabia
}

\begin{abstract}
The purpose of this paper is to identify the effect of education, age and income toward knowledge and behavior of replacing missing teeth and to assess the prevalence of tooth loss among females residing in Jeddah. A random sample of female residents aged 18 years old and above in Jeddah were surveyed by written questionnaires. Descriptive statistics and Chi-square tests were used. More than half of the subjects (59\%) believed that artificial teeth are not as good as natural teeth. The majority of them $(86 \%)$ were aware that it is better to replace missing teeth, and $(83 \%)$ knew that not replacing missing teeth has bad consequences. Thirty-four percent (34\%) thought it is important to replace missing teeth for only chewing food properly. There were no significant differences among different levels of education. The distribution of missing teeth, artificial teeth and type of prosthesis were significantly affected by age distribution and educational level. More than half of the respondents (64\%) lost their teeth due to caries. Most of the subjects (87\%) brush their artificial teeth daily and $7.9 \%$ wash them with water and soap. In conclusion, different levels of education had no significant effect regarding knowledge concerning artificial teeth, and teeth replacement. Education and age have a significant effect towards missing teeth and type of prosthesis. Income was not a significant factor in relation to missing and artificial teeth, and type of prosthesis in Jeddah, Saudi Arabia. Caries followed by periodontal disease were the main reasons for losing teeth.
\end{abstract}

Keywords. Tooth loss, Artificial teeth, Knowledge, Behaviour.

\section{Introduction}

The incidence of edentulism was correlated with baseline measures of lower income,

Correspondence \& reprint requests to: Dr. Salma A. Bahannan,

P.O. Box 10390, Jeddah 21433, Saudi Arabia.

Accepted for publication: 13 November 2001. Received: 29 January 2000. 
education status, poor oral health, self perceptions of poor general and oral health, absence of regular visits to the dentist, and the number of remaining teeth at baseline. No correlation with gender and geographic region and none of the demographic variables retained significance ${ }^{[1]}$.

In 1993, Haugejordan et al ${ }^{[2]}$ reported that there was a significant effect of education on "losing one or more teeth and of age, sex, and education on getting dentures". Miller and Locker ${ }^{[3]}$ claimed that subjects who lost teeth were significantly more compromised in their oral functions and psychological behaviors. Higher education, income, positive attitudes toward oral health and a regular source of dental care were related to more frequent use of dental care ${ }^{[4-8]}$.

Causes for tooth extraction had large geographical and cultural differences between various countries. In the United States of America, caries and periodontal disease seem to cause an almost equal percentage of tooth $\operatorname{loss}^{[9]}$. In India, Subramanian ${ }^{[10]}$ and Metha ${ }^{[11]}$, it was found that the main cause of dental extraction is periodontal diseases. In Singapore, it was found that periodontal tooth mortality associated with the loss of periodontal attachment and risk groups with advanced periodontitis contributing to major tooth loss in a minority of the population ${ }^{[12]}$.

Caries have been found to be the main cause of tooth loss in a large number of countries $^{[13-21]}$. Researchers in Korea reported that the major oral disease causing tooth loss among youth is dental caries. Although dental caries among Koreans between 35 to 44 years and 65 to 74 years of age has declined somewhat in the past decade ${ }^{[22,23]}$.

In Saudi Arabia, a limited number of epidemiological studies have been carried out to determine the prevalence of oral disease and causes of tooth loss ${ }^{[24-26]}$. In addition, no studies were performed to assess knowledge, attitude and behavior regarding tooth loss in the western area of Saudi Arabia. In 1992, a study was done to find out the reasons for tooth mortality in Saudi Arabia. When all age groups were pooled in both primary and permanent teeth, caries were the causes for extraction in $62.7 \%$ of cases. However, periodontal disease was the major factor in patients over 40 years of age, accounting for $51 \%$. Orthodontic reasons accounted for $4 \%$ of the total number of extractions $^{[27]}$.

The female place is an important part in the Saudi community. There are expected barriers for females in seeking treatment such as difficulties in transportation, going out by themselves, and other socio-cultural differences; for those reasons, females were the target for this study.

The purposes of this study were to: 1) Assess knowledge, attitude, and practice of replacing missing teeth and the effect of socio-demographic factors; 2) Assess the prevalence of tooth loss among females living in Jeddah, Saudi Arabia; and 3) Find out the causes of tooth loss. 


\section{Materials and Methods}

A simple random sample of female residents, aged 18 years old and above in Jeddah were surveyed. A total of 1,300 written questionnaires were distributed at King Abdulaziz University, private and public schools, governmental hospitals, banks, and a university that represented different socio-economical status. Target groups were randomly selected based on different geographic areas and different socio-economical status. The questionaires were self-administered. The teaching staff and students' mothers were requested to answer the questionnaires. Female patients visiting hospitals were randomly selected and given the questionnaire to be answered while sitting in the waiting areas. The same questionnaires were also distributed amongst female staff members and students of King Abdulaziz University. The dental school was excluded from this study, since they have more information regarding dentistry than others.

Several visits were performed in each selected area to follow-up the response of the questionaire in order to increase the response rate of the target group. A total of 525 questionnaires were received. The high non-response rate was due to the reluctance of students to deliver the questionnaires to their mothers. The questionnaire consisted of different questions concerning demographic variables, oral hygiene, tooth loss, and teeth replacement. Descriptive statistics consisting of frequencies and percentages were computed as well as Chi-square tests. The level of significance was set at 0.05 throughout the study.

\section{Results}

Data shows the socio-demographic characteristics of the study sample (Table 1). The largest age group was among 31 to 40 years old. Most of the studied group were married $(73 \%)$ and have children $(77 \%)$. Only $8 \%$ of the sample were illiterate, more than half of them $(65 \%)$ had a monthly income of less than SR10,000.

The effect of education on knowledge and attitude toward replacing missing teeth and artificial teeth is displayed (Table 2). Only 12\% of the respondents believed that artificial teeth are as good as the natural teeth, whereas $59 \%$ believed they were not. There was no significant difference among different levels of education. Most of the women $(86 \%)$ were aware that it is better to replace missing teeth, while $83 \%$ knew that not replacing missing teeth had bad consequences. Again, there were no significant differences among different levels of education $(\mathrm{P}<0.05)$.

Almost half of the women (44\%) reported that reasons for replacing missing teeth were the prevention of caries and periodontal disease from affecting the remaining teeth as well as restoring the ability to chew food properly. About one-third (34\%) thought it is important only to chew food properly, while one-tenth (10\%) did not know the reasons. Again, there were no significant differences among different levels of ed- 
ucation. Nearly all subjects $(99.8 \%)$ preferred natural teeth instead of fixed or removable prostheses.

TABLE 1. Socio-demographic characteristics

\begin{tabular}{|c|c|}
\hline Characteristics & Percentage (\%) \\
\hline \multicolumn{2}{|l|}{ Age (in years) } \\
\hline $16-20$ & 4.0 \\
\hline $21-30$ & 29.1 \\
\hline $31-40$ & 44.4 \\
\hline Over 40 & 22.5 \\
\hline \multicolumn{2}{|l|}{ Marital Status } \\
\hline Single & 15.8 \\
\hline Married & 73.3 \\
\hline Divorced & 6.1 \\
\hline Widow & 4.8 \\
\hline \multicolumn{2}{|l|}{ Level of Education } \\
\hline Illiterate & 8.0 \\
\hline Primary & 8.8 \\
\hline Secondary & 10.9 \\
\hline High School & 18.7 \\
\hline Graduate & 41.9 \\
\hline Post Graduate & 11.8 \\
\hline \multicolumn{2}{|l|}{ Occupation } \\
\hline Housewife & 35.2 \\
\hline Teacher & 19.6 \\
\hline Student & 17.1 \\
\hline Administrative & 12.4 \\
\hline Employee & 1.3 \\
\hline Doctor & 1.8 \\
\hline Nurse & 13.5 \\
\hline \multicolumn{2}{|l|}{ Income per month (Saudi Riyals) } \\
\hline$<5,000$ & 29.5 \\
\hline $5,000-10,000$ & 36.0 \\
\hline$>10,000$ & 18.9 \\
\hline No Answer & 15.6 \\
\hline
\end{tabular}

Figure 1 shows the percentage of distribution of missing and artificial teeth among different age groups. There were significant differences among them $\left(\mathrm{x}^{2}=53.84, \mathrm{P}<\right.$ 0.00 for some teeth; $\mathrm{x}^{2}=23.06, \mathrm{P}<0.00$ for all teeth; $\mathrm{x}^{2}=48.24, \mathrm{P}<0.00$ for artificial teeth).

Figure 2 shows the percentage distribution of missing and artificial teeth among different levels of education. There were no significant differences among different levels of education $\left(\mathrm{x}^{2}=63.48, \mathrm{P}<0.00\right.$ for some teeth; $\mathrm{x}^{2}=50.67, \mathrm{P}<0.00$ for all teeth; $\mathrm{x}^{2}=$ $10.77, \mathrm{P}<0.05$ for artificial teeth). 
TABLE 2. Level of education toward dental knowledge regarding artificial teeth.

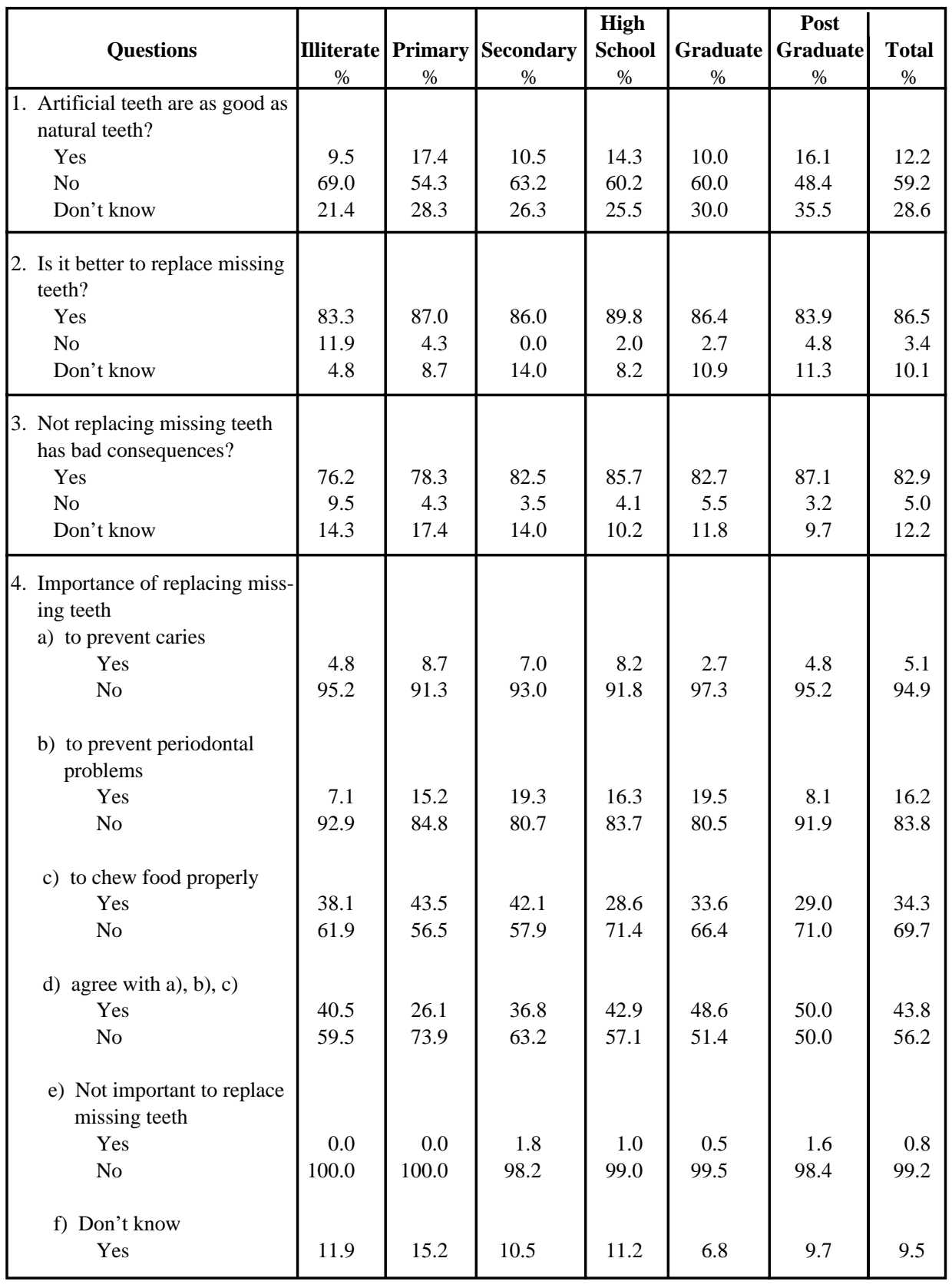






FIG. 1. Distribution of missing and artificial teeth among diffrent age groups. 



(\%) วธิยฺฺววเว 
The distribution of missing and artificial teeth among different levels of income showed that there were no significant differences $\left(x^{2}=6.67, P<0.35\right.$ for some teeth; $x^{2}$ $=2.91, \mathrm{P}<0.23$ for all teeth, $\mathrm{x}^{2}=0.68, \mathrm{P}<0.70$ for artificial teeth).

Figure 3 shows the distribution of the causes of tooth loss. Caries were the primary reason for missing teeth $(64.4 \%)$, and the least frequently given response was for making prosthesis $(2.2 \%)$.

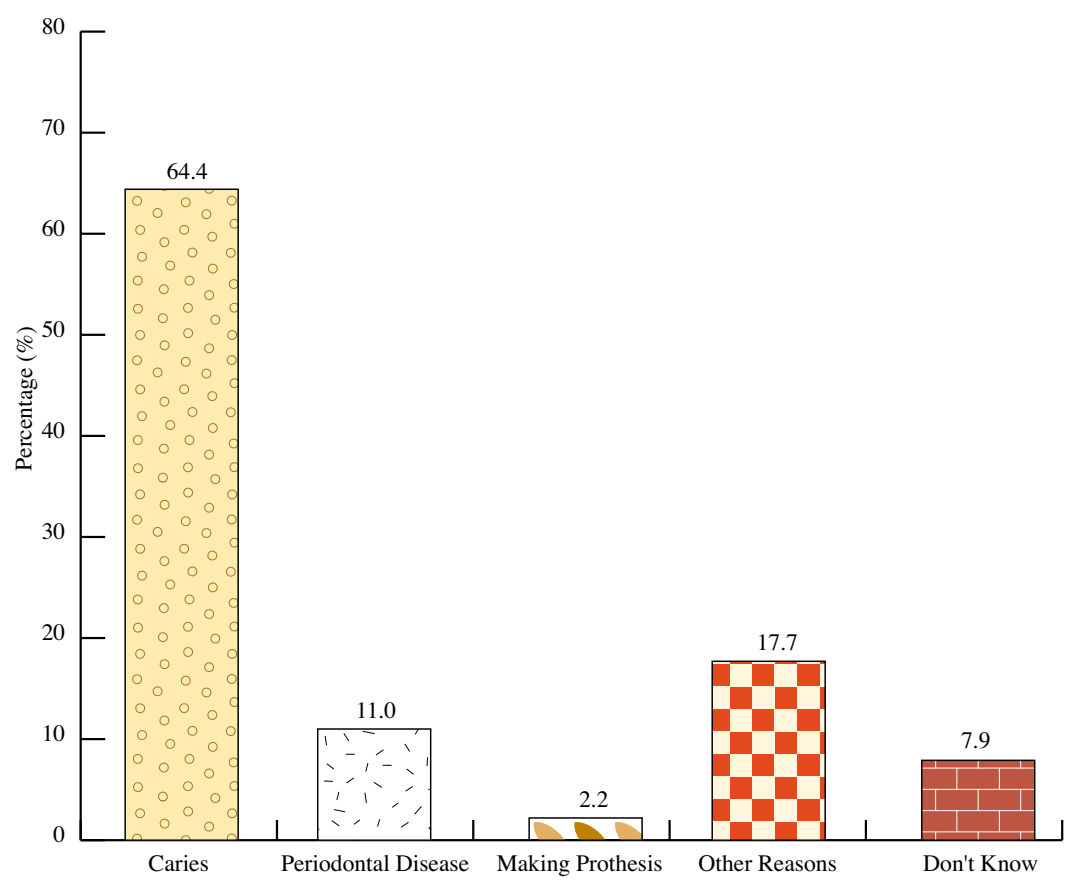

Fig. 3. The distribution of the causes of the missing teeth.

Tables 3, 4, and 5 show the type of prosthesis according to age, education, and income, respectively. There were no significant differences among different levels of age and education only.

Figure 4 shows the distribution of cleaning methods. Eighty-seven percent who have artificial teeth brush their teeth, while $7.9 \%$ wash them with soap and water, $13.3 \%$ mentioned other methods for cleaning their artificial teeth including mouthwash, and dental floss. Only $3 \%$ do not clean their artificial teeth. 
TABLE 3. Type of prosthesis according to age.

\begin{tabular}{|c|c|c|c|c|c|c|c|}
\hline \multirow{2}{*}{\multicolumn{2}{|c|}{ Type of Prosthesis }} & \multicolumn{4}{|c|}{ Age } & \multirow{3}{*}{$\begin{array}{c}\text { Chi-Square } \\
x^{2}=4.15\end{array}$} & \multirow{3}{*}{$\begin{array}{l}\mathrm{P} \text { value } \\
\mathrm{P}<0.24\end{array}$} \\
\hline & & \multirow{2}{*}{$\begin{array}{c}18-20 \\
2 \\
2.2\end{array}$} & \multirow{2}{*}{$\begin{array}{c}21-30 \\
20 \\
22.5\end{array}$} & \multirow{2}{*}{$\begin{array}{c}31-40 \\
42 \\
47.2\end{array}$} & \multirow{2}{*}{$\begin{array}{c}41+ \\
25 \\
28.1\end{array}$} & & \\
\hline Crown & $\begin{array}{l}\mathrm{n} \\
\%\end{array}$ & & & & & & \\
\hline $\begin{array}{l}\text { Fixed } \\
\text { Partial Denture }\end{array}$ & $\begin{array}{l}\mathrm{n} \\
\%\end{array}$ & $\begin{array}{c}0 \\
0.00\end{array}$ & $\begin{array}{c}13 \\
17.3\end{array}$ & $\begin{array}{c}29 \\
38.7\end{array}$ & $\begin{array}{c}33 \\
28.0\end{array}$ & $x^{2}=26.36$ & $\mathrm{P}<0.00^{*}$ \\
\hline $\begin{array}{l}\text { Removable } \\
\text { Partial Denture }\end{array}$ & $\begin{array}{l}\mathrm{n} \\
\%\end{array}$ & $\begin{array}{c}0 \\
0.00\end{array}$ & $\begin{array}{c}0 \\
0.00\end{array}$ & $\begin{array}{c}2 \\
11.8\end{array}$ & $\begin{array}{c}15 \\
88.2\end{array}$ & $x^{2}=43.83$ & $\mathrm{P}<0.00$ \\
\hline $\begin{array}{l}\text { Complete } \\
\text { Denture }\end{array}$ & $\begin{array}{l}\mathrm{n} \\
\%\end{array}$ & $\begin{array}{c}0 \\
0.00\end{array}$ & $\begin{array}{c}0 \\
0.00\end{array}$ & $\begin{array}{c}1 \\
8.3\end{array}$ & $\begin{array}{c}11 \\
91.7\end{array}$ & $x^{2}=33.82$ & $\mathrm{P}<0.00 *$ \\
\hline
\end{tabular}

$* \mathrm{P}$ value $<0.05$

TABLE 4. Type of prosthesis according to education

\begin{tabular}{|c|c|c|c|c|c|c|c|c|c|}
\hline \multirow{2}{*}{ Type of Prosthesis } & \multicolumn{7}{|c|}{ Level of Education } & \multirow{2}{*}{$\begin{array}{l}\text { Chi } \\
\text { Square }\end{array}$} & \multirow{2}{*}{$\begin{array}{c}\mathrm{P} \\
\text { value }\end{array}$} \\
\hline & & Illiterate & Primary & Secondary & \begin{tabular}{|l} 
High \\
School
\end{tabular} & Graduate & $\begin{array}{c}\text { Post } \\
\text { Graduate }\end{array}$ & & \\
\hline \multirow{2}{*}{ Crown } & $\mathrm{n}$ & 5 & 6 & 5 & 19 & 38 & 16 & \multirow{2}{*}{$x^{2}=7.85$} & \multirow{2}{*}{$\mathrm{P}<0.16$} \\
\hline & $\%$ & 5.6 & 6.7 & 5.6 & 21.3 & 42.7 & 25.8 & & \\
\hline \multirow{2}{*}{$\begin{array}{l}\text { Fixed } \\
\text { Partial Denture }\end{array}$} & $\mathrm{n}$ & 6 & 8 & 9 & 11 & 31 & 10 & \multirow{2}{*}{$x^{2}=1.39$} & \multirow{2}{*}{$\mathrm{P}<0.92$} \\
\hline & $\%$ & 8.0 & 10.7 & 15.8 & 14.7 & 41.3 & 13.3 & & \\
\hline \multirow{2}{*}{$\begin{array}{l}\text { Removable } \\
\text { Partial Denture }\end{array}$} & $\mathrm{n}$ & 6 & 5 & 0 & 2 & 1 & 3 & \multirow{2}{*}{$x^{2}=33.21$} & \multirow{2}{*}{$\mathrm{P}<0.00 *$} \\
\hline & $\%$ & 35.3 & 29.4 & 0.0 & 11.8 & 5.9 & 17.6 & & \\
\hline \multirow{2}{*}{$\begin{array}{l}\text { Complete } \\
\text { Denture }\end{array}$} & $\mathrm{n}$ & 8 & 1 & 0 & 1 & 2 & 0 & \multirow{2}{*}{$x^{2}=58.19$} & \multirow{2}{*}{$\mathrm{P}<0.00^{*}$} \\
\hline & $\%$ & 66.7 & 8.3 & 0.0 & 8.3 & 16.7 & 0.0 & & \\
\hline
\end{tabular}

$* \mathrm{P}$ value $<0.05$

TABLE 5. Type of prosthesis according to income

\begin{tabular}{|c|c|c|c|c|c|c|}
\hline \multirow{2}{*}{ Type of Prosthesis } & \multicolumn{4}{|c|}{ Income in Saudi Riyals } & \multirow{2}{*}{ Chi-Square } & \multirow{2}{*}{$P$ value } \\
\hline & & $<5,000$ & $5,000-10,000$ & $>10,000$ & & \\
\hline \multirow{2}{*}{ Crown } & $\mathrm{n}$ & 18 & 36 & 20 & & \multirow[b]{2}{*}{$P<0.10$} \\
\hline & $\%$ & 24.3 & 48.6 & 27 & $x^{2}=4.50$ & \\
\hline \multirow{2}{*}{$\begin{array}{l}\text { Fixed } \\
\text { Partial Denture }\end{array}$} & $\mathrm{n}$ & 16 & 32 & 18 & \multirow[b]{2}{*}{$x^{2}=4.01$} & \multirow[b]{2}{*}{$\mathrm{P}<0.13$} \\
\hline & $\%$ & 24.2 & 48.5 & 27.3 & & \\
\hline \multirow{2}{*}{$\begin{array}{l}\text { Removable } \\
\text { Partial Denture }\end{array}$} & $\mathrm{n}$ & 6 & 5 & 3 & \multirow[b]{2}{*}{$x^{2}=0.42$} & \multirow[b]{2}{*}{$\mathrm{P}<0.80$} \\
\hline & $\%$ & 42.9 & 35.7 & 21.4 & & \\
\hline \multirow{2}{*}{$\begin{array}{l}\text { Complete } \\
\text { Denture }\end{array}$} & $\mathrm{n}$ & 7 & 2 & 1 & \multirow[b]{2}{*}{$x^{2}=5.51$} & \multirow[b]{2}{*}{$P<0.06$} \\
\hline & $\%$ & 70.0 & 20.0 & 10.0 & & \\
\hline
\end{tabular}




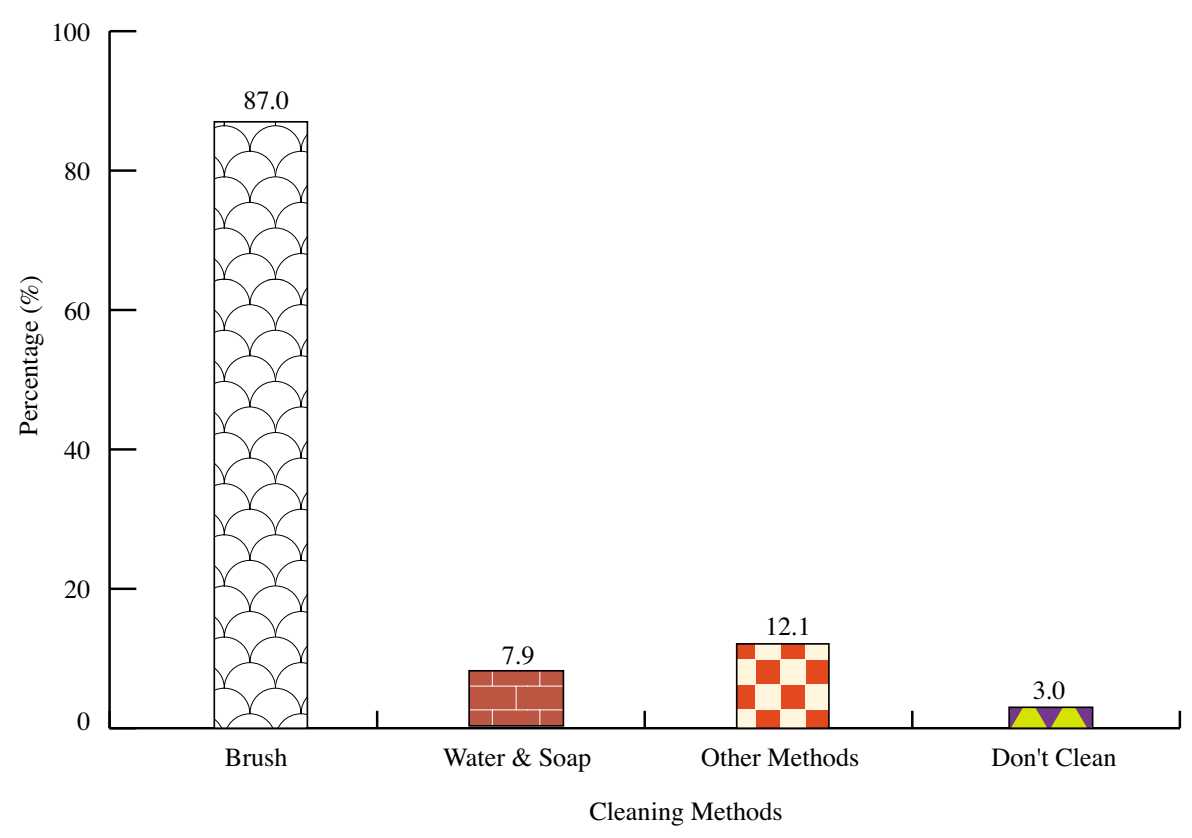

Fig. 4. The distribution of cleaning methods.

\section{Discussion}

The low response rate was one of the limitations of this study. The difficulty of reaching the target population added to this limitation. Although this study was based only on a comprehensive questionnaire, clinical examinations would have added more valuable data. In this survey, it appears that there is no difference among different levels of education in the knowledge regarding artificial teeth and the importance of replacing missing teeth. Although half of the respondents believed that natural teeth are better than artificial teeth, one-third did not know why, which indicates the importance of conducting the dental education programmes stressing the value of maintaining natural teeth.

The mass media, e.g., using television and radio programs, could be a successful educational tool pertaining to all levels of society. In addition, dentists should take time for oral hygiene instructions for every patient. This can be achieved through a dental educational program conducted on a yearly basis to all dentists concentrating on improving the oral health status of patients as prevention is better than treatment.

Most of the subjects (87\%) knew that it is better to replace missing teeth. Regarding the reasons for replacing missing teeth, half of the respondents $(44 \%)$ believed that it is important to prevent caries and periodontal problems, as well as, to chew food properly. The majority of the respondents $(99.8 \%)$ preferred natural teeth. 
There was a significantly higher proportion of tooth loss among the $<40$ years group compared to the 18 to 20 years old group (nearly twice). In the Cohen et al study ${ }^{[20]}$, the highest number of extracted teeth was presented in the 51 to 60 year age group. This age trend seems to support the fact that the proportion of artificial teeth increases with the progression of age.

From the findings of this study, it appears that there is a link between the level of education and the percentage of missing teeth and teeth replacement. This study was in agreement with Haugerjordan's study, who found that there is a marked effect of education on losing one or more teeth ${ }^{[2]}$. However, Eklund and Burt ${ }^{[1]}$ reported that the incidence of edentulism was correlated with baseline measures of lower income and educational status.

There were no significant differences among different income levels for missing teeth. Free dental health services in the Saudi government, including hospitals, polyclnics, and dental schools can be a contributing factor.

There has been considerable variation in reasons for tooth extraction in different countries. It was found, in this study, that caries are the main cause of missing teeth $(64.9 \%)$ followed by periodontal disease $(11.5 \%)$. This is in agreement with the Farsi study ${ }^{[26]}$ who found that caries were the leading cause of extraction in Saudi Arabia (62.7\%) followed by periodontal disease. Only $2.5 \%$ of the respondents reported that extraction was done for prosthetic reasons, while $18 \%$ reported other reasons such as orthodontic indications, impacted teeth and wisdom teeth.

This study was in agreement with others studies ${ }^{[27,28,29]}$, since tooth brushing was well established as a daily routine in all groups $(87 \%)$.

Of the patients, $7.9 \%$ reported using soap and water to clean their artificial teeth. Others mentioned using mouth wash, dental floss and chewing sticks (miswak) ${ }^{[25]}$. Elwin-Lewis $e{ }^{a} l^{[30]}$ reported that tooth loss was minimal in populations where such natural tooth cleaning devices were used.

There was a significant difference among different age groups and types of prosthesis. The number of fixed partial dentures, removable partial dentures, and complete dentures increases in the proportion of partial and complete dentures.

It was discovered that there was no significant difference among different types of prosthesis according to different levels of income. This might be due to the available free dental services provided by the government hospitals and polyclinics in Saudi Arabia.

Based on the findings, the following conclusions can be drawn: 1) Different levels 
of education have no significant effect towards knowledge concerning artificial teeth and missing teeth replacement, 2) Education and age have a significant effect on the proportion of missing teeth and types of prosthesis, while income was not a significant factor, and 3) Caries followed by periodontal disease were the main reasons for losing teeth.

It is recommended to implement special dental health educational programmes targeting Saudi females to increase their level of oral health knowledge and behavior in maintaining their teeth in a healthy condition.

\section{Acknowledgment}

The author would like to extend her sincere appreciation to Dr. Nazeer Khan, King Saud University. Special thanks to Prof. Mahassen Farghaly, King Abdulaziz University, for her valuable advice.

\section{References}

[1] Euklund SA, Burt BA. Risk factors for tooth loss in United States, longitudinal analysis of national data. J Public Health Dent 1994; 54(1): 5-14.

[2] Haugejordan O, Rise J, Klock KS. Norwegian adults perceive the need for coping skills to adjust to dental and non-dental life events. Community Dent \& Oral Epidemiol 1993; 21: 57-61.

[3] Miller Y, Locker D. Correlates of tooth loss in a Canadian adult population. J Can Dent Assoc 1994; 60(6): 549-555.

[4] Dolan TA, Corey CR, Freeman HE. Older American's access to oral health care. J Dent Educ 1988; 52(11): 631-642.

[5] Kiyak HA. Explaining patterns of dental service utilization among the elderly. J Dent Educ 1986; 50 (11): $679-687$.

[6] Evashwick C, Conrad D, Lee F. Factors related to utilization of dental services by the elderly. Am J Public Health 1982; 72(10): 1129-1135.

[7] Wolinsky FD, Arnold CL. A birth cohort analysis of dental contact among elderly Americans. Am J Public Health 1989; 79(1): 47-51.

[8] Tenstedd SL, Brambilla DI, Jette AM, McGuire SM. Understanding dental service use by older adults: socio-behavioral factors vs. need. J Public Health Dent 1994; 54: 211-219.

[9] American Dental Association. Survey for dental care, Bureau of Economic Research and Statistics. Am Dent Assoc Chicago 1965.

[10] Subramanian V. Causes for the extraction of teeth amongst hospital patients. J Indian Dent Assoc 1951; 23: 5-6.

[11] Metha FS, Sanjara MK, Shrott BC. Analysis of periodontal disease as a cause of tooth loss. J Indian Dent Assoc 1960; 32: 71-76.

[12] Ong G. Periodontal disease and tooth loss. Int Dent J 1998; 48: 233-238.

[13] Coxhead VL. Reasons for extraction in general practice. New Zealand Dent Fluoridation 1960; 56: $182-183$ 
[14] Johansen SB, Johansen JR. A survey of causes of permanent tooth extractions in South Australia. Aust Dent J 1977; 22: 238-242.

[15] Trott JR, Cross HG. An analysis of the principle reasons for tooth extractions in 1,813 patients in Manitoba. Dent Pract Dent Rac 1966; 17: 29-37.

[16] Ainamo J, Sarkki L, Kuhalampi ML, Palolampi L, Purto O. Frequency of periodontal extractions in Finland. Comm Dent Health 1984; 1: 165-172.

[17] Loe H, Anerud A, Boysen H, Smith M. The natural history of periodontal disease in man. J Periodont Res. 1978; 13: 563-572.

[18] Kay EJ, Blinkhorn AS. The reasons underlying the extraction of teeth in Scotland. Br Dent J 1986; 160: $287-290$.

[19] Razak IA, Jaafer N, Matnor G. The causes of tooth mortality of permanent teeth in a Malaysian population. J Irish Dent Assoc 1989; 35: 39-41.

[20] Cohen PM, Frank PM, Turiot JC. A survey of the reasons for dental extractions in France. J Dent Res 1990; 64: 1087-1093.

[21] Lundquist C. Tooth Mortality in Sweden. A statistical survey of tooth loss in Swedish population. Acta Odont Scand 1967; 25: 289-321.

[22] Park KJ. Survey on the tooth loss among Koreans. J Kor Acad Dent Health 1981; 5: 52-54.

[23] Kang SY, Kim JB. A study on the causes and needs for extraction of teeth among Koreans. J Kor Acad Dent Health 1983; 7: 7-20.

[24] Al Khateeb TL, O'Mullane, Whelton H, Sulaiman MI. Periodontal treatment needs among Saudi Arabian adults and their relationship to the use of the Miswak. Comm Dent Health 1991; 8: 323-328.

[25] Basharahil H. The prevalence of dental caries in Saudi school children using the chewing stick (Miswak) and those using the tooth brush. Indonesian Dent $J$ 1986; 46: 45-51.

[26] Farsi JM. Common causes of extraction of teeth in Saudi Arabia. Saudi Dent J 1992; 4: 101-105.

[27] Payne BJ, Locker D. Preventive oral health behaviors in a multi-cultural population: the North Uork Oral Health Promotion Survey. J Can Dent Assoc 1994; 60: 129-130.

[28] Westover W. Results of seniors' oral health survey in rural Alberta. Probe 1999; 33: 57-62.

[29] Lin HC, Wong MC, Wang ZJ, Lo EC. Oral health knowledge, attitudes, and practice Chinese adults. J Dent Res 2001; 80: 1466-1470.

[30] Elwin-Lewis M, Kevall K, Lewis WH, Harwood M. The anticariogenic potential of African chewing sticks. J Dent Res 1974; 55-277. 


\title{
دراسـة تأثير المعلومات والسلو كيات عـلى فتـــان الأسنـان وتعويضهـا
} بأ سنان صناعيـة بين الإناث السعوديات في جـدة

\author{
سلمى باحنان \\ قسم إعادة تأهيل الوجه والفكين ، كاحنان \\ كلية طب الأسنان ، جامعة الملك عبدالعزيز، العين، \\ جـــة - المملكة العربية السعودية
}

المستخلص. تمت دراسة تأثير المستوى التعليمى والعمـر والدخل

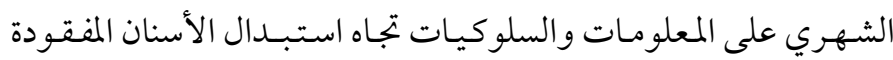
بأسنان صناعية، ونسبة انتشار فقدان الأسنان بين الإناث في مدينة جدان التحة.

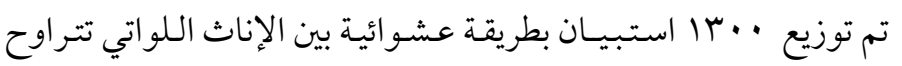

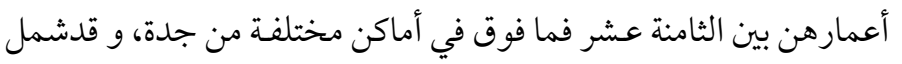

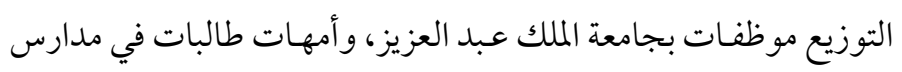

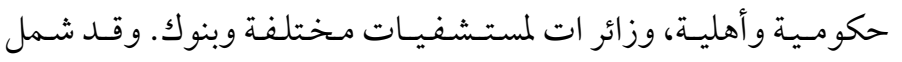

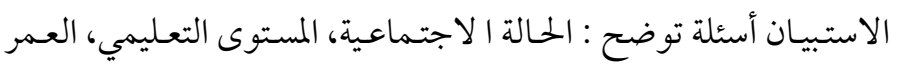

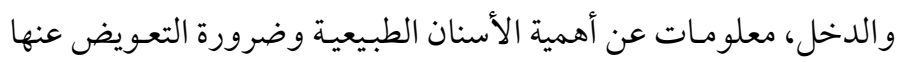

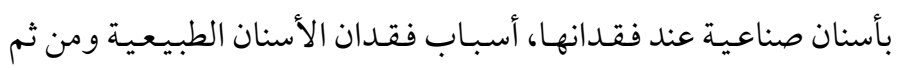



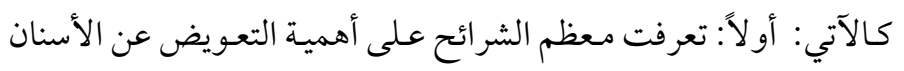

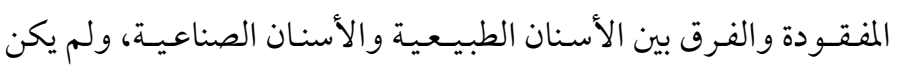

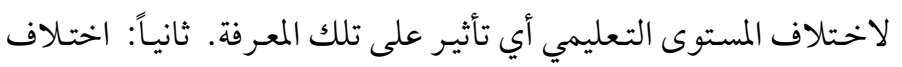

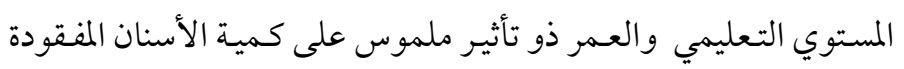
ونوعية الثركيبات المستخدمة، أما اختلاف الدخر مل الثل الشهري فلائا تأثير له. 


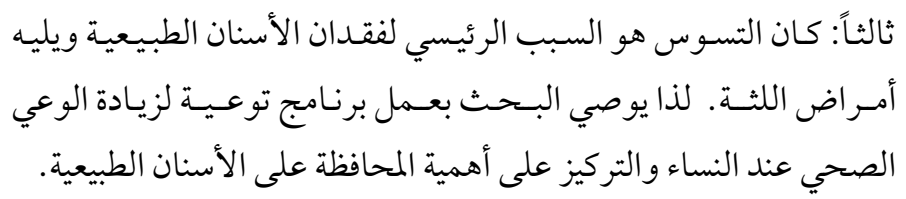

